\title{
Cost analysis of different brands of antimicrobial agents available in India
}

\author{
Shakeel Ahmad Mir*
}

Department of Clinical

Pharmacology, Sher-I-Kashmir

Institute of Medical Sciences

(SKIMS), Srinagar, Kashmir,

India

Received: 08 December 2015

Accepted: 07 January 2016

\section{*Correspondence to:}

Dr. Shakeel Ahmad Mir, Email: drshakeelahmadmir @ gmail.com

Copyright: (C) the author(s), publisher and licensee Medip Academy. This is an openaccess article distributed under the terms of the Creative Commons Attribution NonCommercial License, which permits unrestricted noncommercial use, distribution, and reproduction in any medium, provided the original work is properly cited.

\begin{abstract}
Background: A major reason why patients go-off regimen is the cost of drugs. In the global market, the cost of drugs is highly variable. In India, there are more than five hundred pharmaceutical manufacturers and most of the drugs are available in brands. Infectious and parasitic diseases are among the major causes of death worldwide. The greatest burden of infectious disease is found in developing countries. Many of these people could be cured if they receive appropriate treatment such as antimicrobials. People usually purchase the amount of drug they can afford and not what they need for total cure. If a clinician prescribes a cheaper effective brand, it could result in reduction of drug cost as well as total health-care costs. Clinicians cannot be expected to know the exact cost of each drug available in the market, but it would be helpful if they had some impression of the cost variation between different effective brands of the same generic drug. The objective of this study was to analyse the cost (acquisition cost) variation in different brands of commonly used antimicrobials in India.
\end{abstract}

Methods: The minimum and the maximum cost in Rupees (INR) of a particular antimicrobial agent manufactured by various pharmaceutical companies in the same strength were noted. The cost of 10 tablets, 10 capsules or 1 injection was calculated. The cost ratio and Percentage cost variation were calculated for each brand.

Results: A great variation was found in the cost of different brands of same antibiotic. Percent cost variation of (2000) was found for Ciprofloxacin $500 \mathrm{mg}$ tablet, followed by (1830) for Imipenem one Gram vial. The lowest percent cost variations found were: Tigecycline $50 \mathrm{mg}$ vial (9), Teicoplanin $400 \mathrm{mg}$ vial (25), Acyclovir $800 \mathrm{mg}$ tab (32), Vancomycin $1 \mathrm{G}$ vial (40), and Lomefloxacin $400 \mathrm{mg}$ tablet (72).

Conclusions: Since there is a significant cost variation in different brands of same generic antimicrobial agent, clinicians need to consider drug cost while prescribing. If the clinician prescribes the cheapest of the effective brands available, it will help keep costs down and improve patient compliance.

Keywords: Cost analysis, Antimicrobials, Compliance, Adherence, Branded Drugs, Pharmaceuticals

\section{INTRODUCTION}

Pharmaceutical costs are the fastest-growing health-care expense. ${ }^{1}$ The consideration of cost of treatment for ailments is an important aspect in health economics. ${ }^{2}$ The cost of the drug plays a crucial role in patient care especially in developing countries. Financial constraints are a reality in almost all aspects of a medicine. Pharmaceutical expenditure is increasing faster than other areas of health care spending. ${ }^{3}$ It has been observed that there is a gross variation in the cost of different brands of same generic Drug. ${ }^{2}$ Different economic evaluation techniques are used to analyze the cost of medicines or total health care costs. Price is the amount of money to purchase an item and cost is the total resources consumed in producing a good or service. One of the most important aspects of calculating a medicine`s cost is acquisition cost or medicine price. ${ }^{4}$

India enjoys an important position in the global pharmaceutical sector. Presently the market size of the pharmaceutical industry in India stands at US \$20 billion. 
As on March 2014, Indian pharmaceutical manufacturing facilities registered with the US food and drug administration (FDA) stood at 523, highest for any country outside the US. ${ }^{5}$ Many patients in developing countries find it difficult to afford standard medicines which leads to poor or non-compliance. A large survey found that a significant percentage of high income respondents also indicated cost related non-compliance. ${ }^{6}$ To deal with the issue of affordability and availability of medicine, the Government of India introduced mechanisms such as drug price control order and the National Pharmaceutical Pricing Authority. Drug Price Control Orders (DPCOs) are issued by the government for enabling the government to declare a ceiling price for essential and lifesaving medicine. ${ }^{5}$

Cost related poor patient compliance is a worldwide problem. Poor or non-compliance affects clinical outcome and increases healthcare costs. The links between poor antimicrobial compliance and antimicrobial resistance have been clearly demonstrated in chronic infections like Tuberculosis. $^{7}$

In the global market, cost of drugs is highly variable and therefore obtaining accurate and relevant costs is very important. Clinician's awareness of cost of therapeutics is poor. ${ }^{1}$ They must have better cost awareness, otherwise they may continue to prescribe more expensive drugs.

The present study was aimed at investigating the acquisition cost differences in various brands of the same generic antimicrobial agent, so that whenever possible, a cheaper effective brand can be prescribed to ensure better compliance and reduce drug cost as well as total healthcare costs.

\section{METHODS}

Prices of various antimicrobial agents were obtained from the latest issue of Drug today (Oct-Dec, 2015). ${ }^{8}$

1. The minimum and the maximum cost in Rupees (INR) of a particular antimicrobial manufactured by various pharmaceutical companies in the same strength were noted.

2. The cost of 10 tablets, 10 capsules or 1 injection was calculated.

3. The cost ratio, the ratio of the cost of the costliest to cheapest brand of the same generic antimicrobial was calculated. This tells, how many times costliest brand costs more than the cheapest one in each generic group. ${ }^{2}$

4. Percentage cost variation was calculated as follows:

$\%$ cost variation $=\frac{\text { Maximum cost }- \text { minimum cost }}{\text { Minimum cost }} \times 100^{9}$

5. Fixed dose combinations (FDCs), paediatric and topical antimicrobial preparations were not analyzed in this study.

\section{RESULTS}

This study shows that there is a great variation in the prices of different brands of same antimicrobial agent in Indian market. The highest cost ratio (1:21) and percent cost variation (2000) was found for Ciprofloxacin $500 \mathrm{mg}$ tablet, followed by cost ratio $(1: 19.30)$ and percent cost variation(1830) for Imipenem one Gram vial. Other significant percent cost variations were: Clarithromycin $250 \mathrm{mg}$ tablet (1358), Amikacin $500 \mathrm{mg}$ vial(1283) Clarithromycin $500 \mathrm{mg}$ tablet (1275), Terbinafine $250 \mathrm{mg}$ tablet (1136), Itraconazole $100 \mathrm{mg}$ cap (1019), Amoxycillin $250 \mathrm{mg}$ cap(824), Ofloxacin $200 \mathrm{mg}$ tablet(522), Doxycycline $100 \mathrm{mg}$ tablet(516), Ketoconazole $200 \mathrm{mg}$ tablet (499), Cefpodoxime $200 \mathrm{mg}$ tablet (480) Ofloxacin $400 \mathrm{mg}$ tablet (444), Norfloxacin $400 \mathrm{mg}$ tablet (401), Azithromycin $250 \mathrm{mg}$ tablet (344). The lowest percent cost variations found were: Tigecycline $50 \mathrm{mg}$ vial (9), Teicoplanin $400 \mathrm{mg}$ vial (25), Vancomycin $1 \mathrm{G}$ vial (40), Lomefloxacin $400 \mathrm{mg}$ tablet (72) (Table 1).

\section{DISCUSSION}

Compliance or adherence is the extent to which the time history of drug administration corresponds to the prescribed regimen. ${ }^{7}$ Patients are considered adherent to medications when they take prescribed drugs at doses and times recommended by health care provider. ${ }^{10}$ Poor patient compliance is a worldwide problem. It affects clinical outcomes and increases health care costs. The links between poor compliance and antimicrobial resistance has been clearly demonstrated in chronic infections like tuberculosis. ${ }^{7}$ Factors that contribute to patient non-compliance with antibiotic therapy include: cost of drugs, formulation, rapid improvement of symptoms, forgetfulness, frequent dosing, side effects, and patient beliefs. ${ }^{11}$ According to Planning Commissions report (2014), $30.9 \%$ of the rural population and $26.4 \%$ of the urban population was below the poverty line in 201112. The all-India ratio was $29.5 \%$. In rural India, 260.5 million individuals were below poverty and in urban India, 102.5 million were under poverty. Totally, 363 million were below poverty in 2011-12. ${ }^{12}$ With global budgets a concern and the welfare of patients at risk, clinicians need to consider drug cost when prescribing. However in most places cost information is not easily available for clinicians. Globally the costs of drugs are highly variable. ${ }^{1}$ This study reveals that in Indian market also the prices of antimicrobials are highly variable. The results of this study are consistent with other studies conducted in India., ${ }^{2,13}$

There is consistent lack of appreciation of the large differences in cost between inexpensive and expensive drugs. ${ }^{1}$ Clinician's ignorance of drug costs result in prescription of costly drugs, when cheaper alternatives are available. This often causes non-compliance or nonadherence. In order to improve adherence clinicians must choose the least costly medication. Since the superiority 
of any costliest brand over the cheapest one has never been scientifically established, a conscientious prescriber should always choose the cheapest brand while prescribing. ${ }^{14}$

Table 1: Price analysis of different antimicrobial agents.

\begin{tabular}{|c|c|c|c|c|c|}
\hline Group/drug & Strength & $\begin{array}{l}\text { Min cost } \\
\text { (INR) }\end{array}$ & Max cost (INR) & Cost ratio & $\%$ cost variation \\
\hline \multicolumn{6}{|l|}{ Penicillins } \\
\hline Ampicillin & 500 mg cap & 50 & 74.50 & $1: 1.5$ & 49 \\
\hline \multirow[t]{2}{*}{ Amoxycillin } & 250 mg cap & 5.30 & 49 & $1: 9.2$ & 824 \\
\hline & $500 \mathrm{mg}$ cap & 44 & 79 & $1: 1.8$ & 79 \\
\hline \multicolumn{6}{|l|}{ Macrolides } \\
\hline \multirow{2}{*}{ Azithromycin } & $250 \mathrm{mg}$ tab & 36 & 160 & $1: 4.4$ & 344 \\
\hline & $500 \mathrm{mg}$ tab & 103 & 218 & $1: 2.1$ & 112 \\
\hline Roxithromycin & $150 \mathrm{mg}$ tab & 46 & 94.83 & $1: 2.1$ & 106 \\
\hline \multirow[t]{2}{*}{ Clarithromycin } & $250 \mathrm{mg}$ tab & 24 & 350 & $1: 14.6$ & 1358 \\
\hline & $500 \mathrm{mg}$ tab & 50 & 687.50 & $1: 13.75$ & 1275 \\
\hline \multicolumn{6}{|l|}{ Cephalosporins } \\
\hline Cefixime & $200 \mathrm{mg}$ tab & 56 & 490 & $1: 8.7$ & 775 \\
\hline Cephotaxime & $1 \mathrm{G}$ vial & 25 & 110 & $1: 4.4$ & 340 \\
\hline Ceftriaxone & $1 \mathrm{G}$ vial & 35 & 98 & $1: 2.8$ & 180 \\
\hline \multirow[t]{2}{*}{ Cefuroxime } & $250 \mathrm{mg}$ tab & 87 & 411 & $1: 4.7$ & 372 \\
\hline & $500 \mathrm{mg}$ tab & 229 & 884 & $1: 3.9$ & 286 \\
\hline Cefpodoxime & $200 \mathrm{mg} \mathrm{tab}$ & 90 & 522.50 & $1: 5.8$ & 480 \\
\hline \multicolumn{6}{|l|}{ Carbapenems } \\
\hline Imipenem & $1 \mathrm{G}$ vial & 139.90 & 2700 & $1: 19.3$ & 1830 \\
\hline \multicolumn{6}{|l|}{ Glycopeptides } \\
\hline Vancomycin & $1 \mathrm{G}$ vial & 275 & 385 & $1: 1.4$ & 40 \\
\hline Teicoplanin & $400 \mathrm{mg}$ vial & 1275 & 1600 & $1: 1.2$ & 25 \\
\hline \multicolumn{6}{|l|}{ Oxazolidinones } \\
\hline Linezolid & $600 \mathrm{mg}$ tab & 299 & 900 & $1: 3$ & 201 \\
\hline \multicolumn{6}{|l|}{ Tetracyclines } \\
\hline Doxycycline & $100 \mathrm{mg} \mathrm{tab} / \mathrm{cap}$ & 8.76 & 54 & $1: 6.1$ & 516 \\
\hline \multicolumn{6}{|l|}{ Glycylcyclines } \\
\hline Tigecycline & $50 \mathrm{mg}$ vial & 2790 & 3031.71 & $1: 1.1$ & 9 \\
\hline Chloramphenicol & $500 \mathrm{mg}$ cap & 44 & 85 & $1: 1.93$ & 93 \\
\hline \multicolumn{6}{|l|}{ Fluoroquinolones } \\
\hline Norfloxacin & $400 \mathrm{mg}$ tab & 9.93 & 49.72 & $1: 5$ & 401 \\
\hline \multirow[t]{2}{*}{ Ciprofloxacin } & $250 \mathrm{mg}$ tab & 19.50 & 69.85 & $1: 3.6$ & 258 \\
\hline & $500 \mathrm{mg}$ tab & 5.95 & 125 & $1: 21$ & 2000 \\
\hline Gemifloxacin & $320 \mathrm{mg}$ tab & 198 & 718 & $1: 3.6$ & 263 \\
\hline \multirow[t]{2}{*}{ Sparfloxacin } & $100 \mathrm{mg}$ tab & 27.50 & 99.50 & $1: 3.6$ & 262 \\
\hline & $200 \mathrm{mg}$ tab & 75 & 250 & $1: 3.3$ & 233 \\
\hline Pefloxacin & $400 \mathrm{mg}$ tab & 17.15 & 47 & $1: 2.7$ & 174 \\
\hline Lomefloxacin & $400 \mathrm{mg}$ tab & 90 & 155 & $1: 1.7$ & 72 \\
\hline Moxifloxacin & $400 \mathrm{mg}$ tab & 55 & 700 & $1: 12.7$ & 1173 \\
\hline \multirow[t]{2}{*}{ Ofloxacin } & $200 \mathrm{mg}$ tab & 24.95 & 155.32 & $1: 6.2$ & 522 \\
\hline & $400 \mathrm{mg}$ tab & 48.95 & 266.28 & $1: 5.4$ & 444 \\
\hline Prulifloxacin & $600 \mathrm{mg}$ tab & 500 & 990 & $1: 2$ & 98 \\
\hline \multirow[t]{2}{*}{ Levofloxacin } & $250 \mathrm{mg}$ tab & 19 & 51 & $1: 2.7$ & 168 \\
\hline & $500 \mathrm{mg}$ tab & 40 & 101 & $1: 2.5$ & 152 \\
\hline \multicolumn{6}{|l|}{ Sulfonamides } \\
\hline Cotrimoxazole & DS tab & 10.60 & 17.50 & $1: 1.6$ & 65 \\
\hline Antifungals & & & & & \\
\hline
\end{tabular}




\begin{tabular}{|llllll|}
\hline Ketoconazole & $200 \mathrm{mg} \mathrm{tab}$ & 57.90 & 347 & $1: 6$ & 499 \\
\hline Terbinafine & $250 \mathrm{mg} \mathrm{tab}$ & 72 & 890 & $1: 12.4$ & 1136 \\
\hline Fluconazole & $150 \mathrm{mg} \mathrm{cap} / \mathrm{tab}$ & 98 & 380.60 & $1: 3.9$ & 288 \\
\hline Itraconazole & $100 \mathrm{mg}$ cap & 68 & 761.20 & $1: 11.2$ & 1019 \\
\hline Antivirals & & & & & \\
\hline Acyclovir & $800 \mathrm{mg} \mathrm{tab}$ & 200 & 263.50 & $1: 1.3$ & 32 \\
\hline Antiprotozoal & & & & & \\
\hline Metronidazole & $400 \mathrm{mg} \mathrm{tab}$ & 6.31 & 11.96 & $1: 1.9$ & 89 \\
\hline Ornidazole & $500 \mathrm{mg} \mathrm{tab}$ & 44.63 & 90 & $1: 2$ & 102 \\
\hline Tinidazole & $300 \mathrm{mg}$ tab & 7.99 & 26.90 & $1: 3.4$ & 237 \\
\hline Secnidazole & $1 \mathrm{G} \mathrm{tab}$ & 157.50 & 227.15 & $1: 1.4$ & 44 \\
\hline Albendazole & $400 \mathrm{mg} \mathrm{tab}$ & 52.50 & 160 & $1: 3$ & 205 \\
\hline Ivermectin & $6 \mathrm{mg} \mathrm{tab}$ & 100 & 160 & $1: 1.6$ & 60 \\
\hline
\end{tabular}

According to World Health organization (W.H.O) half the world's population is too poor to pay for many of the drugs they need from their own resources even at the lowest possible prices. ${ }^{15}$ People purchase the amount of drug they can afford and not what they need to be cured for. This leads to under treatment or treatment failure. Treatment failure plays a crucial role in emergence of resistant strains. ${ }^{16}$

\section{CONCLUSION}

Many patients find it difficult to afford standard antibiotic medication, which leads to non-compliance and increases over all health care costs. If clinicians are not aware that large cost differences exist in different brands of the same generic drug, they may continue to prescribe the more expensive ones, which ultimately results in noncompliance. This study was aimed to get an overview of price variation in different brands of the same antimicrobial agent available in India. A significant cost variation was found in this study. Clinicians need to be educated about this cost variation. High cost of therapy is one of the important contributing factors for patient noncompliance. To control the drug cost and total health-care costs clinicians must prescribe the least costly medication when there are no substantial differences in safety and effectiveness between the least and most costly.

\section{Limitations}

1. Fixed dose combinations, paediatric and topical preparations were not analyzed in this study.

2. Prices of only commonly used antimicrobial agents were analyzed in this study.

Funding: No funding sources

Conflict of interest: None declared

Ethical approval: Not required

\section{REFERENCES}

1. Allan GM, Lexchin J, Wiebe N. Physician awareness of drug cost: A systematic review. PLoS Med. 2007;4(9):e283.

2. Gupta RK, Reddy PS. A calm look on cost analysis of different brands of anti-epileptic drug. J MGIMS. 2011;16(i):64-6.

3. OECD Health Division (2006) OECD Health Data 2006, October 06. Available: http://www.oecd.org/dataoecd/20/51/37622205.xls. Accessed 3March 2007)

4. Management Sciences for Health (MSH). Evaluating the Cost of Pharmaceuticals. 2007. Available at http://www.who.int/medicines/technical_briefing/tbs 106-TG_Evaluating-drug-costs_final-08.pdf. Accessed 12.12.2015.

5. India in business. Ministry of External affairs, Govt. of India. Investment and Technology Promotion Division. Available at http://indiainbusiness.nic.in/newdesign/index.php?pa ram=industryservices_landing/347/1. Accessed 12.12.2015.

6. Piette JD, Beard A, Rosland AM, McHorney CA. Beliefs that influence cost-related medication nonadherence among the "haves" and "have nots" with chronic diseases. Patient Prefer Adherence. 2011;5:389-96.

7. Kardas P, Bishai WR. Compliance in infective medicine. Adv Stud Med.2006;6(7C):S652-58

8. Drug Today. October-December. 2015;23(2):359548.

9. Akila L, Rani RJ. Cost analysis of different brands of antianginal drugs available in India. Int J Basic Clin Pharmacol. 2015;4:860-3.

10. Osterberg L, Blaschke T. Adherence to medication. N Engl J Med. 2005;353(5):487-97.

11. SCOPE: Pharmacist's Guide to Judicious Usage of Antibiotics.https://cme.dannemiller.com/scope/articl es/activity? $\mathrm{id}=428 \& \mathrm{p}=12$. Accessed 12.12.2015.

12. Planning Commission Govt. of India 2014. Report of the expert group to review the methodology for measurement of poverty. Available at http://planningcommission.nic.in/reports/genrep/pov _rep0707.pdf. Accessed 12.12.2015. 
13. Andayani T M, Imaningsih I. Cost analysis of antidiabetic drugs for diabetes mellitus out patient in Kodya Yogyakarta hospital. Malay J pharm Sci. 2007;5(1):19-23.

14. Lal A, Sharma ML. A calm look at the cost of drugs in psychiatric practice. Indian J. PsychiaL 1992;34(1):18-20

15. World Health organization (WHO). Report of the Workshop on Differential Pricing \& Financing of Essential

Drugs.

Available
http://apps.who.int/medicinedocs/en/d/Jh2951e/2.1.h tml. Accessed 12.12.2015.

16. Uppsala universitet. Economical access to antibiotics in an era of increasing resistance - a study from Lahore, Pakistan(CR). Available at http://www.farmfak.uu.se/farm/exjob/diplomawork/ VT10BinaAzhar.pdf. Accessed 12.12.2015.

Cite this article as: Mir SA. Cost analysis of different brands of antimicrobial agents available in India. Int J Basic Clin Pharmacol 2016;5:85-9. 